HID 47 (2020)

\title{
LA IMAGEN DEL OBISPO IDEAL EN LA REVUELTA DE LAS COMUNIDADES DE CASTILLA (1520-1521)
}

\author{
THE IMAGE OF THE IDEAL BISHOP IN THE REVOLT OF \\ THE COMUNIDADES OF CASTILE (1520-1521)
}

\section{Claudio CÉSAR RizzUto \\ Universidad de Buenos Aires \\ claudiorizzuto88@gmail.com ORCID: https://orcid.org/0000-0003-4298-4207}

RESUMEN: la tradición del obispo ideal posee una larga trayectoria en la historia del cristianismo. El siglo XVI fue uno de los momentos en que más se discutió este punto, con interés particular por reformar las costumbres del clero en Europa Occidental. Los reinos hispánicos no fueron ajenos a este movimiento, en especial entre los intentos de reforma propuestos por los Reyes Católicos y el Concilio de Trento. Entre estos dos procesos, la revuelta de las Comunidades de Castilla (1520-1521) presentó el esbozo de un programa de reforma eclesiástica y de los obispos en particular. Entre los diferentes escritos de los rebeldes y en el contexto del levantamiento puede hallarse la disputa por una imagen del obispo y sus tareas.

PAlabras ClaVE: Revuelta Comunera; obispo ideal; reforma eclesiástica; iglesia local; Castilla.

ABSTRACT: The tradition of the ideal bishop has a long trajectory in the history of Christianity. The Sixteenth Century was one of the moments of more discussion on this topic, with particular interest on reforming the habits of the clergy in West Europe. The Hispanic kingdoms were not out of this movement, especially for the attempts of reform proposed of the Catholic Kings and the Council of Trent. Between these two processes, the revolt of the Comunidades of Castile (1520-1521) outlined a program of ecclesiastical reform including the bishops. Among the different documents of the rebels and within the context of the uprising, the dispute for an image of the bishop and his tasks can be found.

KEYWORDS: Comunero Revolt; ideal bishop; ecclesiastical reform; local church; Castile.

Recibido: 23-9-2019; Aceptado: 13-1-2020; Versión definitiva: 17-2-2020.

Copyright: (C) Editorial Universidad de Sevilla. Este es un artículo de acceso abierto distribuido bajo los términos de la licencia de uso y distribución Creative Commons Reconocimiento-NoComercialSinObraDerivada 4.0 (CC BY-NC-ND 4.0) 


\section{INTRODUCCIÓN}

La reflexión sobre el lugar de los obispos en la Iglesia Católica Romana fue un importante tópico de discusión a mediados del siglo pasado ${ }^{1}$. El Concilio Vaticano II sirvió de culminación de una larga tradición de orientación pastoral del episcopado, enfatizando su condición de sucesores de los apóstoles. Como puede percibirse en cualquier obra de síntesis eclesiológica posterior a estas transformaciones, el episcopado ha cobrado una fuerte importancia a nivel pastoral y teológico, aspecto que ha influido fuertemente en la historiografía ${ }^{2}$. En este contexto, se produjeron distintos estudios dedicados a la reforma eclesiástica en España y al rol del episcopado en la historia del cristianismo en la Península. Diferentes trabajos, siguiendo la obra de Hubert Jedin desde los años '40 dedicada al ideal de obispo, estudiaron la trayectoria del episcopado entre la llamada reforma de los Reyes Católicos y la aplicación del concilio de Trento. Así, los trabajos de Tarsicio de Azcona, José Ignacio Tellechea Idígoras o Juan López Martín, dedicados a la reforma del episcopado y a la imagen del obispo entre los siglos XV y XVI, aparecen como las principales referencias en la historiografía española ${ }^{3}$.

Por otra parte, se han desarrollado una gran cantidad de estudios dedicados especialmente al poder temporal de las instituciones eclesiásticas de la Edad Moderna $^{4}$. En este marco, los obispos han sido una referencia para el estudio tanto del poder a nivel local en sus diócesis como en la interrelación con los poderes temporales y el papado. Aparecen así problemas como el poder señorial, el crecimiento urbano, la iglesia y los estudios prosopográficos o el problema del llamado estado moderno ${ }^{5}$.

Por último, diferentes estudios se han ocupado de la relación de los obispos con las poblaciones de sus diócesis en relación con lo que se ha llamado la reforma de las costumbres o directamente la "cristianización" en los términos del célebre libro de Jean Delumeau'. Estos estudios también han permitido, en especial al momento de estudiar el catolicismo después de Trento, colocar a los obispos como protagonistas y acercarse a sus figuras de una manera más compleja, alejada de considerar un obispo ideal y confrontarlo con cada uno de los nombres de los episcopologios ${ }^{7}$.

1. Se utilizará Iglesia con mayúscula cuando remita a una idea de Iglesia como comunidad universal de fieles, y con minúscula cuando se haga referencia a una iglesia local particular.

2. Algunos ejemplos en obras eclesiológicas: Kung 1968, pp. 461-565; Pié-Ninot 2009, pp. $371-$ 427; González Montes 2008, pp. 261-277.

3. Azcona 1958, 1960, 1980, 1986; Tellechea Idígoras 1963; López Martín 1971.

4. Ejemplos pioneros en este sentido: Delumeau 1957 y 1959 ; Hill 1956.

5. Una obra de síntesis para la corona de Castilla, desde una perspectiva socioeconómica para el período posterior al de este estudio: Barrio Gozalo 2000.

6. Delumeau 1973, pp. 217-250.

7. Para el caso castellano, el principal estudio en este sentido es: Nalle 1992. El gran estudio sobre la aplicación del concilio de Trento en España: Fernández Terricabras 2001. Sobre la delegación española en Trento también puede consultarse el clásico: Gutiérrez 1951. En el caso francés puede consultarse: Peyrous 1995. Para el caso italiano, Milán en particular: De Boer, 2001. Para el caso catalán: Sola Colomer 2008. 
En este marco se puede abordar el pensamiento comunero sobre los obispos. Si bien el mismo puede ubicarse fácilmente en toda una tradición occidental, su aparición en una revuelta permite colocarlo en relación con otros problemas considerados por los textos en ella producidos. Ante cierta imagen de obispo ideal que se ubicará entre los rebeldes, aparecerá también una visión que consideraba otras dimensiones como la centralización monárquica y su influencia en la Iglesia, el rol del prelado cortesano, la disposición de los bienes episcopales, entre otros ${ }^{8}$. Cabe destacar, como ha hecho Alison Forrestal para la Francia del siglo XVII, que las visiones de los obispos no eran unánimes y que muchos obispos presentaron una realidad mucho más compleja, donde tareas administrativas y políticas podían conciliarse con funciones espirituales ${ }^{9}$. De este modo, las críticas comuneras deberán ubicarse en realidades disimiles, donde los valores y principios eran múltiples, a pesar que a primera vista parece haber existido cierta unanimidad en sus declaraciones.

\section{LOS OBISPOS EN LOS CAPÍTULOS COMUNEROS}

La revuelta de las Comunidades de Castilla generó una importante cantidad de escritos de los cuales se han conservado una serie de capítulos que se refieren a múltiples aspectos del reino como la hacienda, los órganos de gobierno, la iglesia, la justicia, la producción de textiles, la moneda y hasta las maneras de tratar a los pueblos de América ${ }^{10}$. Los problemas relativos al mundo eclesial son diversos y aparecen en una serie de peticiones, como la cuestión de la Bula de Cruzada, los beneficios eclesiásticos o las órdenes religiosas. Aquí se analizarán las demandas relativas a los obispos ${ }^{11}$. Cabe aclarar que los rebeldes realizaron una serie de peticiones al rey en las que dependiendo del carácter que se les otorgue a las mismas se caracterizará de manera diferente a todo el movimiento. Los capítulos conservados son varios, pero puede sugerirse que cada ciudad habría generado sus propios escritos, ya que si bien los principales refieren a la unión de los representantes de todas las ciudades rebeldes en sus diferentes lugares de reunión como Ávila y Tordesillas, otros serían de ciudades en particular, como Burgos, Valladolid o Jaén. A su vez, se cuenta con información sobre la producción de capítulos en otras

8. El reino de Francia suele ser el caso paradigmático para el estudio de las relaciones entre la monarquía y la Iglesia y el clero, en especial debido al llamado "galicanismo". Al respecto: Parsons 2004; Pierre 2013. Para el caso castellano en el período tardo medieval: Nieto Soria 1993. Para Castilla en tiempos de Carlos V: Perrone 2008. Para otros dominios españoles, en el caso de Sicilia, puede consultarse: D’Avenia 2015.

9. Forrestal 2004

10. Si bien todos los trabajos sobre las Comunidades se han ocupado de dichos capítulos, algunos autores han hecho mayor énfasis en ellos, llegando a hablar en algunos casos de "labor constitucional". Han tratado con especial interés el contenido de los mismos: Belmonte Díaz 1986; Jerez 2007; Peralta, 2010.

11. Para un tratamiento en extenso de los diferentes aspectos de la Iglesia castellana en los capítulos comuneros: Jerez 2007, pp. 511-566. 
ciudades como Toledo y Córdoba ${ }^{12}$. Si bien una reflexión sobre el papel de los obispos no suele ocupar un lugar central en dichos capítulos, su presencia puede hacerla objeto de análisis historiográfico. Además, como se verá, la misma no se trató de una referencia aislada respecto de los prelados sino que puede vincularse con posiciones sobre otras demandas realizadas por los comuneros.

La figura del obispo posee una larga trayectoria en el pensamiento cristiano: casi todos los grandes referentes del cristianismo del primer milenio fueron obispos, muchos entre los llamados Padres de la Iglesia. A su vez, dicha figura fue objeto de reflexión recurrente, muchas veces acompañada de la función sacerdotal en general, con referentes como Juan Crisóstomo, Gregorio Magno, Ambrosio de Milán y Bernardo de Claraval. Allí se han buscado durante siglos los textos clásicos sobre el actuar de los obispos, enfatizándose particularmente la dimensión pastoral y apostólica ${ }^{13}$. Los siglos XV y XVI, antes y después del estallido de la Reforma, tuvieron un auge del razonamiento sobre los mismos, en primer lugar vinculado a las propuestas conciliares de la época del Gran Cisma de Occidente, con figuras como Pierre d'Ailly, en segundo lugar en los albores de la Reforma con personajes como Gasparo Contarini ${ }^{14}$. Efectivamente, a partir de Trento, como se ha mencionado, la literatura al respecto fue in crescendo y se recuperó una imagen del obispo Santo, propia del primer cristianismo, con figuras como Carlos Borromeo y Francisco de Sales ${ }^{15}$.

En un contexto de un mayor control de las iglesias episcopales por parte de los reyes castellanos, las Cortes plantearon la necesidad de otorgar los cargos a personas naturales del reino, aspecto muchas veces reclamado por los mismos monarcas, en cambiantes relaciones con el Papado. Si bien este punto aparecía entre los comuneros como preocupación general a todos los cargos, incluidos seglares, la mención de los obispos en la revuelta puede vincularse con una orientación pastoral así como con el lugar de los prelados, y de la iglesia en general, en la sociedad ${ }^{16}$. Este aspecto puede percibirse ya en los cuadernos de Cortes de los siglos XIV y XV. Mucho se ha escrito sobre la cuestión del rechazo de los extranjeros para la ocupación de los cargos entre los comuneros. No obstante, como ha mostrado Ana Arranz Guzmán, el pedido en contra de la extranjería de los beneficiados en el caso episcopal, o de otros beneficios eclesiásticos, solía ir acompañado de una visión integral del problema, ya que como consecuencia de

12. Sobre la elaboración y autoría de los capítulos/instrucciones: Jerez 2007, pp. 100-108. Sobre la participación del clero en la construcción del programa comunero: Diago Hernando, 2007, pp. 109-115.

13. Sobre los obispos en la eclesiología alto medieval: Congar 1968, pp. 138-151.

14. Sobre Pierre d'Ailly y el episcopado: Pascoe 2005, pp. 53-164. Sobre Gasparo Contarini: Tramontin 1965; Gleason 1993, pp. 91-110. Para otros ejemplos de autores venecianos sobre la imagen del obispo ideal: Logan 1978. Sobre los obispos y el inicio de la Reforma en Inglaterra: Cartelon 2001.

15. Sobre el ideal de obispo en la época de Trento y después, la citada obra de Jedin, en su adaptación francesa: Broutin 1953. También: Almeida do Rolo 1965; Tellechea Idígoras 1963. Dos breves resúmenes: Bédouelle 2003, pp. 79-83; Po-Chia Hsia 2010, pp. 139-155.

16. Sobre los distintos intentos por evitar la incorporación de extranjeros en las provisiones eclesiásticas: Hermann 1986; Rouco Varela, pp. 245-251. Para el problema de nacionalidad y extranjería en la Revuelta Comunera: Pietschmann 1992; Vicente Blanco 2015. 
estos nombramientos: se retiraban dineros del reino, se avalaba el ausentismo de los obispos nombrados, se generaba indisciplina eclesiástica, se perdía reciprocidad entre los diferentes prelados castellanos, se abandonaba a los fieles, y se provocaba desánimo para pagar el diezmo, entre otros ${ }^{17}$. Por ejemplo, en las Cortes de 1506, la petición 11 reclamaba:

Muy grand daño se ha rrecreçido e recresçe enestos reynos por proueer a los estranjeros obispados e denidades e venefiçios especialmente aquellos que rresyden en corte rromana; $y$ paresçe el daño en lo espiritual, porque nunca rresyden en sus yglesias, y siguese el daño temporal, por quelas rrentas de obispados e denidades que tienen sacan en oro e en plata destos rreynos para llevar a Roma e a otras partes fuera dellos: suplican a Vuestas Altezas que no se provean de obispados e denidades e venefiçios a estranejros, ni se den cartas de naturalezas, e las que están dadas, se reuoquen, e con mucho rrecabdo se provea en que los tales no saquen oro, ni plata, ni moneda destos rreynos ${ }^{18}$.

De esta manera, la cuestión de la extranjería era ampliada con diferentes aspectos de los problemas de la Iglesia castellana. Asimismo, la preocupación por los recursos también merece cierta aclaración. En adición al problema económico que podía provocar la fuga de dinero de las ciudades y del reino, para los fieles era una vía relativamente aceptada el pago de dinero para obtener distintos beneficios salvíficos, como ha mostrado Patrick J. O'Banion a partir de la popularidad de la Bula de Cruzada en el siglo XVI ${ }^{19}$. Por tanto, no se debe abandonar de plano una posible dimensión religiosa cada vez que se encuentra dinero mencionado en asuntos eclesiásticos.

En el caso comunero, la postura de los rebeldes puede ubicarse alrededor de muchas de estas corrientes, a su vez que las ubicaba en un contexto político y social más amplio ${ }^{20}$. Dicho ideal episcopal, que nunca logró imponerse completamente, pretendía desplazar hacia el espacio de las diócesis a la jerarquía de la Iglesia, quitando su protagonismo político, consolidando así cierto retroceso de la Iglesia como totalidad de lo social ${ }^{21}$. A su vez, se ponía en duda un aspecto fundamental del desarrollo administrativo temprano moderno, vinculado con el surgimiento de formas estatales, que resultaba de la colaboración de los prelados con las monarquías en el ejercicio de numerosas funciones como la diplomacia o hasta el mismo gobierno $^{22}$. De esta manera, puede percibirse la intervención de los rebeldes en algunos de los problemas eclesiásticos de la época, que a su vez se relacionaban con

17. Arranz Guzmán 1990, pp. 730-739. Cabe destacar asimismo, que el pedido de que el obispo surgiera del clero local respondía a la más antigua tradición eclesiástica, a pesar de haber sido abandonada y haberse mantenido luego como un elemento de disputa, cfr. González Faus 1992, p. 45 y passim.

18. Cortes de los antiguos reinos de León y Castilla 1861-1903, vol. IV, p. 227.

19. O’Banion 2010.

20. Sobre los comuneros y los beneficios eclesiásticos puede consultarse: Morán Martín 2018.

21. Sobre este aspecto: Iogna-Prat 2016.

22. Un recuento de los prelados en el gobierno de Carlos V: Azcona 1986, p. 279. 
aspectos fundamentales del devenir de las sociedades europeas. Luego de estas aclaraciones, pueden citarse las diferentes posiciones de los comuneros.

Una primera declaración se recoge en los capítulos de la ciudad de Valladolid donde se afirmaba:

se deben proveer que los obispos residan en sus obispados e que no auden en la corte ni estén fuera de sus obispados especialmente todos los del rreyno de granada pues que ay tanta necesidad questen con ellos ${ }^{23}$.

Luego de pedir la residencia de los obispos en sus diócesis, se destacaba que no estuvieran en la corte, señalando el apoyo que brindaban al rey en múltiples tareas administrativas o diplomáticas. A su vez, acentuaban la necesidad pastoral en el reino de Granada, conquistado a los musulmanes décadas atrás, pero con importantes problemas para la evangelización de la población, según se desprende de numerosos testimonios ${ }^{24}$. En este caso, además, se trataba de una crítica directa al presidente del Consejo Real, Antonio de Rojas, arzobispo de Granada y acérrimo enemigo de los revoltosos ${ }^{25}$. Llegar al Consejo Real podía ser una dignidad en la carrera eclesiástica incluso superior a los obispados, con la posibilidad de convertirse en presidente del mismo, como era el caso de Antonio de Rojas y otros siete prelados en el siglo XVI. Obviamente, podían también incorporarse a otros Consejos de la monarquía ${ }^{26}$. Así, lejos de ser una crítica en abstracto, puede percibirse una clara direccionalidad en atacar a los grandes personajes del gobierno del rey, siendo además Granada sede de ilustres obispos que enfatizaron la tarea pastoral antes y después de la revuelta como los casos de Hernando de Talavera, Pedro de Alba y Pedro Guerrero ${ }^{27}$.

Los capítulos de Burgos, ciudad mucho más moderada en su participación en la revuelta, avanzaron en el mismo sentido:

porque es muy notorio el dapño que en estos reynos ay por estar absentes los perlados de sus diócesis. E aun los que se han de hordenar hacen muchos gastos e espensas, y reciben muchos dapños y fatygas que su magestad mande proveer que los tales prelados resydan en su diócesis y quando por necesidad oviere de yr alguna parte del en ellos, pues pueden otros en su lugar que lo tal pueden hazer ${ }^{28}$.

23. Capítulo 60, Capítulos de la ciudad de Valladolid, reproducidos en Jerez 2007, p. 616.

24. Sobre la cristianización de Granada: Coleman 2003; Harris 2007.

25. Sobre la actitud de este prelado ante los comuneros puede consultarse: Pérez 1999, pp. 282-283.

26. Morgado García 2000, p. 67.

27. Sobre Hernando de Talavera: Iannuzzi 2009. Sobre Pedro Guerrero: Marín Ocete 1970; López Martín 1971. La figura de Pedro de Alba, criado en la Granada de Talavera, a pesar de haber sido obispo por dos años, resulta sumamente célebre por tratarse de uno de los protagonistas del Dialogo de la Doctrina Cristiana atribuido a Juan de Valdés y publicado anónimamente en Alcalá de Henares en 1529. Sobre Juan de Valdés, Pedro de Alba y la influencia de Hernando de Talavera: Pastore 2010, pp. 257-280; Santiso 2014, pp. 235-237.

28. Capítulo 32, capítulos de la ciudad de Burgos, en Jerez 2007, p. 631. Todos los capítulos comuneros, excepto los de Jaén, se encuentran reproducidos como apéndice en este libro. 
En Burgos se agregaba a la enumeración de Valladolid el coste económico del ausentismo de los obispos. Se sugiere al rey buscar alternativas a utilizar prelados en determinadas tareas, de modo de no dañar las diócesis. Aquí tampoco se trataba de una crítica en abstracto, ya que Burgos era otra ciudad que poseía un obispo con importantes tareas seglares, el célebre Juan Rodríguez de Fonseca, responsable de los negocios americanos y enemigo de los comuneros ${ }^{29}$.

Los capítulos de Tordesillas, ya no propios de esa villa sino de la reunión de la Junta instalada allí por la presencia de la reina Juana, declaraban:

que los arzobispos, obispos, perlados de estos reinos residan en sus diócesis la mayor parte del año, e que non lo haciendo, pierdan por rata los frutos, e sean para las fábricas de las iglesias, por no residir en ellas, no son servidas, ni administrados los divinos oficios como deberían. E que Su Alteza envie por bula de Su Santidad para ello dentro de un año a estos reinos. E que si en el dicho término Su Alteza no la enviare, que el reino tenga facultad de la haber de nuestro muy Santo Padre e tomar por su autoridad de los frutos de las dignidades de lo que se desprendiere en haber la dicha bula e costa dello ${ }^{30}$.

En este caso, adicionaron una clausula ante la ausencia de prelado: la pérdida de los recursos que surgieran de su cargo, de modo que pasaran a las fábricas de las iglesias. Se alude al principio latino Prorata o pro rata que establecía la proporcionalidad, en este caso el obispo ausente perdería los recursos proporcionalmente a la duración de la misma: si se ausentaba un año, lo correspondiente a un año. Además, se solicitaba que el rey realizase una petición al Pontífice para el plazo de un año y se amenazaba con la posibilidad de actuar en las ciudades en caso que Carlos no quisiera acceder. Cabe destacar que el ausentismo era un problema fundamental de todo el sistema beneficial de la Iglesia del Antiguo Régimen, en especial antes de las regulaciones tridentinas que instalaron con más fuerza las funciones de vicario, coadjutor o teniente. Mientras tanto, el ausentismo provocaba la necesidad de tenientes que reemplazaban a los ausentes, pero que muchas veces no poseían experiencia, conocimiento, o no lograban el respeto de los parroquianos, con graves consecuencias para la práctica religiosa ${ }^{31}$. Dicho problema afectaba a todo tipo de beneficios eclesiásticos y ha sido uno de los elementos cruciales a la hora de caracterizar la llamada "crisis eclesiástica" de los siglos XIV y XV $\mathrm{XV}^{32}$.

En las declaraciones comuneras aparecería claramente la intención de atribuirse un rol en el gobierno de la Iglesia por parte de los poderes urbanos, en este caso pudiendo comunicarse con el Papa sin necesidad de la mediación monárquica. Si bien se presentaba bajo cierta excepcionalidad, en caso de no intervenir el rey, no dejaba de establecer un principio de posibilidad. Asimismo, el impedimento

29. Probablemente este personaje fuese uno de los grandes ejemplos del modelo de obispo que se intentaba combatir, apegado a una carrera burocrático-administrativa. Sobre Fonseca y los comuneros: Szászdi León-Borja 2009.

30. Capítulo 102, capítulos de Tordesillas, en Jerez 2007, p. 652.

31. Barrio Gozalo 2010b, p. 19.

32. Chiffoleau 2011, pp. 38-46. 
de trasladar recursos y que se mantengan para la fábrica de las iglesias puede conservar ciertos ecos conciliaristas a nivel diocesano como han resaltado autores como John B. Owens o José Joaquín Jerez como inspiración de las ideas políticas comuneras: el obispo era cabeza de la iglesia local en tanto estaba unido a ella, en presencia, no podía existir la cabeza separada de su cuerpo ${ }^{33}$. Sin embargo, ya la tradición teológica previa a los tiempos del conciliarismo establecía que la existencia misma de una iglesia local dependía de la presencia de un obispo en tanto jefe y guía de la comunidad ${ }^{34}$. Asimismo, el capítulo colocaba el oficio por encima del beneficio, se debía cumplir con las tareas para recibir las ventajas que el obispado otorgaba. En palabras de Francisco de Vitoria, años después de la revuelta y referido a todos los beneficios eclesiásticos: terrible cosa es que pague diezmos el labrador a quien nunca vio ${ }^{35}$. La metáfora del cuerpo místico, tantas veces mencionada para aspectos gubernamentales, estaría puesta en duda: para ser parte del todo se debía estar físicamente ${ }^{36}$.

Por último, los capítulos de fray Francisco de los Ángeles, resultado de la mediación de este general de la Orden Franciscana entre realistas y comuneros, afirmaba:

que se suplique a su Santidad que los Obispos y Arzobispos e prelados destos Reynos residan en sus obispados la mayor parte del año e que no lo faziendo pierdan porrata los frutos e sean para las fabricas de las Iglesias pues por no residir en ellas no son servidas ni administrados los oficios divinos como devian e que su magestad enbie bulla de su Santidad para ello a estos Reynos ${ }^{37}$.

Aquí se hablaba de modo muy similar al anterior capítulo citado, que se pierdan los recursos en caso de ausencia y que se pida al Papa que lo cumpliese. Puede ser indicio de un tono de negociación, la ausencia de la referencia que serían las ciudades quienes demandarían al Sumo Pontífice en caso de que el rey no lo hiciese. A su vez, se agregaban las consecuencias que esto tenía para los oficios divinos, destacando claramente la preocupación pastoral de los rebeldes. Lejos

33. Sobre las ideas conciliares en los años previos de la revuelta: Jerez 2007, pp. 497-501. John B. Owens, en cambio, establece no sólo cierta influencia del conciliarismo sino un rol fundamental a la hora de construir el ideario político de la revuelta: Owens 2005, pp. 102-113. Pablo Fernández Albaladejo señalaba que la concepción conciliarista que la cabeza nunca podía ser más que el cuerpo -que el rey no podía tener más poder que todo el reino- tuvo una influencia fundamental en la tratadística castellana del siglo XVI: Fernández Albaladejo 1992, p. 82.

34. Palazzo 2004, p. 70.

35. Francisco de Vitoria. "Carta que escribió el padre Fray Francisco de Vitoria al doctor Luis Gomez, criado del cardenal don Juan Tauera sobre cosas de beneficios y residencias", reproducida como apéndice en: Tellechea Idígoras 1963, pp. 107-110, aquí p. 108.

36. Cabe destacar que la metáfora del cuerpo místico para referir al obispo y su cabildo posee una larga trayectoria, que persiste en el siglo XVII por ejemplo en la obra del arcediano Juan Machado de Chaves, cfr. Morgado García 2000, p. 36. Para el estudio de la idea de Corpus mysticum en la Iglesia la obra clásica es: Lubac 2009. Para la historia política occidental, la obra clásica es Kantorowicz 2012. Para el caso español: Maravall 1973. Para el siglo XVI: Nieto 1997, pp. 375-411. Sobre la idea del cuerpo político en el humanismo: Capelli 2012.

37. Capítulo 84, capítulos de Fray Francisco de los Ángeles, en Jerez 2007, pp. 663-664. 
de ser un tema secundario, Hubert Jedin y Paul Broutin han destacado que en la figura de Jean Gerson, por ejemplo, se encuentra la cuestión de la cura animarum como el problema crucial del movimiento reformista del fin de la Edad Media ${ }^{38}$. A su vez, para Tellechea Idígoras la preocupación por la orientación pastoral de los obispados caracterizaba todo el pensamiento sobre los obispos del siglo XVI, aún más luego de Trento, considerando tópicos como el bonus pastor y destacando la orientación religiosa de su tarea por sobre la dimensión secular en todas sus variantes, sea como colaborador de los reyes o como poseedor de señoríos ${ }^{39}$. El arzobispo Pedro Guerrero, clave en la representación española en la última etapa del concilio, llegó a sugerir que la residencia era de tal manera de derecho divino que ni el Papa podía dispensarla, de modo de volver imposible la situación de obispos dedicados a otras actividades ${ }^{40}$. De allí, por ejemplo, la idea inicial de la Compañía de Jesús según la cual sus miembros no podían asumir cargos ni ocuparse de tareas seglares ${ }^{41}$. Cabe destacar, que la residencia resultaba fundamental a la hora de construir la imagen del obispo como destinado por el Espíritu Santo, cuestión sumamente discutida durante todo el concilio, en especial por la delegación española ${ }^{42}$. Esta coincidencia entre postulados de las ciudades, en este caso las comuneras, y las propias del concilio de Trento se expresaba también en la formación general del clero no sólo los obispos, según se desprende de las Cortes de todo el siglo $\mathrm{XVI}^{43}$. Sin embargo, debe aclararse que la residencia, si bien era muy importante para los clérigos españoles en Trento, en el caso de los prelados franceses se resaltaba no tanto la residencia sino el cumplimiento de las tareas al momento de permanecer allí. De allí, la necesidad de delimitar claramente cuáles eran las tareas del obispo, de modo que pudieran cumplirlas ${ }^{44}$.

Todas las declaraciones comuneras acuerdan en que los prelados deben permanecer en sus diócesis, siendo uno de los grandes problemas de la época. La ejemplaridad del obispo se consideraba fundamental, si el obispo era bueno se creía que el clero de su diócesis sería bueno, si el obispo era cazador el clero sería cazador. Dicha ejemplaridad y coincidencia tuvo cierto éxito después de Trento ${ }^{45}$. No obstante, en tiempos del emperador, Tarsicio de Azcona señalaba que en pocas oportunidades se cumplió, Pero lo más sintomático fue que se rebatieron en ocasiones estos argumentos teológicos y se trató de justificar la irresidencia ${ }^{46}$. De esta manera, si bien prácticamente todo tratado que se ocupaba de la materia incitaba a que los obispos residieran en sus diócesis, siendo un verdadero tópico de la época, se encuentran opiniones contrarias entre los obispos de corte, quienes contaban con una larga tradición desde el período medieval. El célebre caso

\footnotetext{
38. Broutin 1953, 1953, p. 19.

39. Tellechea Idígoras 1963.

40. Cfr. López Martín 1971, p. 55.

41. Cfr. Lozano Navarro 2005, p. 58-61.

42. Jedin 1965, p. 75.

43. Hermann, Christian. Hermann 1976, p. 212.

44. Tallon 2017, p. 721.

45. Barrio Gozalo 2010a, p. 15.

46. Azcona 1980, p. 154.
} 
en este sentido, fundamental en el gobierno del emperador, es el de Fernando de Valdés, Inquisidor General, presidente del Consejo de Castilla y titular de numerosos obispados a lo largo de su vida. Este afirmaba que el deber de residencia era cosa de predicadores y teólogos y que contrario a lo que estos sostenían, el obispo podía dejar un lugarteniente para ocuparse de los asuntos espirituales tal como lo hacía con los asuntos seculares del obispado ${ }^{47}$. En este sentido, además del caso de Acuña que se analizará con mayor detalle, no puede dejar de señalarse a Diego Ramírez de Villaescusa, obispo de Cuenca desde 1518 y que había realizado una larga carrera en la Corte, llegando a capellán de la reina Juana. Villaescusa intentó mediar entre comuneros y realistas, por lo que fue sospechado de rebelde y de compartir algunos de sus objetivos. Si bien nunca fue condenado, escapó a Roma con Adriano de Utrecht, demoró algunos años en volver hasta recuperar el favor real tiempo después, y falleció en su diócesis en $1537^{48}$.

Como ha mostrado C. Stephen Jaeger, ya desde las cortes reales pleno-medievales los obispos tuvieron un rol fundamental. A su vez, muy tempranamente surgieron objeciones clericales a estos personajes, que eran acusados de abandonar la perspectiva del obispo pastor propia de la patrística cristiana ${ }^{49}$. En el caso hispánico, por ejemplo, estas visiones enfrentadas pueden encontrarse en relación con la lucha contra los musulmanes: era un aspecto relativamente aceptado la participación de los obispos y sus ejércitos en la lucha contra el infiel, en general como pastores de los cruzados, aunque en otros casos como jefes guerreros ${ }^{50}$. Un ejemplo controversial en tiempos cercanos a las Comunidades fue Francisco Jiménez de Cisneros, quien además de realizar un enorme esfuerzo por la reforma religiosa en España, protagonizó como arzobispo de Toledo la conquista de Orán, lo que no le dejó de provocar algunas críticas entre diferentes círculos espiritua$1 \mathrm{e}^{51}$. Cabe destacar que, si bien el obispo guerrero, tan célebre en la lucha contra el Islam y en las guerras intestinas del reino de Castilla, tiende a desaparecer en tiempo de los Reyes Católicos, no así el obispo de corte o funcionario, que fue célebre por muchas décadas más ${ }^{52}$. Además, el problema del obispo guerrero relativamente desaparecido en la España temprano moderna, mantuvo vigencia en la América Hispánica en los siglos XVII y XVIII ${ }^{53}$. En este contexto, frente al

47. Cfr. Tellechea Idígoras 1963, pp. 258-259.

48. Sobre este obispo: Fleming 2018; Olmedo 1944; Martínez Soria; Millán Martínez (coords.) 2009.

49. Jaeger 1985. Sobre los obispos y las cortes reales, algunos trabajos en: Lappin; Balzamo 2018.

50. Al respecto: Goñi Gaztambide 1958, pp. 35-38; Arranz Guzmán, 2014, vol. 1, pp. 313-334.

51. Sobre Cisneros y la conquista de Orán: Alonso Acero 2006. Sobre las críticas a Cisneros, en particular del llamado fray Melchor, de alto contenido profético: Pastore 2010, pp. 125-146.

52. Sobre el ocaso de los obispos guerreros, tanto por razones pastorales como propias del desarrollo monárquico: Martínez Ruiz 2018, pp. 42-67. Sobre capellanes militares: García Hernán 2006. Sin embargo, tan tardíamente como 1794 fray Diego de Cádiz en El soldado católico en las guerras de religión, llamaba a todos los sacerdotes a participar de la "guerra santa" contra los revolucionarios franceses, cfr. Morgado García 2000, p. 107-108.

53. El rol de los obispos en la guerra en la América colonial se presenta en especial en las zonas de frontera, realizando planes de ataque y defensa en relación con los "indios" enemigos. Para un panorama general: Mazín 2012. 
Cisneros espiritual tantas veces reivindicado, puede hallarse un Cisneros estadista y político, aspecto que le otorgó fama internacional, por ejemplo, en la Francia del cardenal Richelieu ${ }^{54}$. Como se ve, entrado el siglo XVII, el modelo de clérigo de Corte se encuentra plenamente vigente ${ }^{55}$. Según Maximiliano Barrio Gozalo, a lo largo de toda la Edad Moderna se incrementó la consideración de los obispos como funcionarios del rey, llegando a ser acusados de ser agentes gubernamentales en $1833^{56}$.

Asimismo, con estas peticiones se podía quebrar una alianza fundamental entre la corona y la jerarquía eclesiástica, ya que, a pesar de sostenerse el principio de residencia desde los textos vinculados a la monarquía desde la asamblea de Sevilla de 1478, fueron los reyes quienes saltaron su propio criterio siempre que necesitaron los servicios de los obispos para acompañar a la corte ${ }^{57}$. José Manuel Nieto Soria tomaba los pedidos de residencia de los obispos, como en el pedido en las Cortes de 1295, como intención de las oligarquías urbanas de reivindicar el poder de las ciudades atrayendo a todas las personas importantes a vivir en las mismas ${ }^{58}$. Cabe destacar que además se encontraba un trasfondo doctrinal en el enunciado, rescatando la dimensión pastoral, vinculada también a la defensa de los intereses urbanos como sugiere Nieto Soria, si se toma en cuenta la perspectiva del interés citadino por la salvación de sus habitantes. No debe olvidarse que en muchas ocasiones, el obispo o el tener un obispado propio iba acompañado del honor y engrandecimiento de la ciudad ${ }^{59}$. A su vez, desde la misma perspectiva episcopal, para autores como el mencionado Gasparo Contarini, el obispo debía mantener las virtudes divinas de modo que pudieran emanar desde él a toda la ciudad ${ }^{60}$. De esta manera, los postulados comuneros pueden ubicarse, con mayores o menores diferencias, entre ideas más extendidas y de larga presencia. Asimismo, se los encuentra tanto acompañando, como en el caso las coincidencias con Trento, como disputando, en la oposición al obispo cortesano, algunos de los problemas eclesiásticos del siglo XVI y de buena parte del período temprano moderno.

54. García Oro 1992, vol. I, pp. 473-492; Pérez 2014, pp. 257-276.

55. Sobre la idea de clero de corte (clergé de cour): Pierre 2013, pp. 8-9 y 17-30. Para el caso castellano, esta idea es independiente de cierta decadencia en el prestigio social de los obispos a mediados del siglo XVII, considerado por Helen Rawlings a partir del origen social de los mismos, cfr. Rawlings 1987. Un estudio socio-económico de los obispos desde el reinado de Felipe II: Barrio Gozalo 2000 .

56. Barrio Gozalo 2004, p. 57.

57. Azcona 1980, p. 154.

58. Nieto Soria 1997, p. 95. El pedido de las Cortes de Valladolid de 1295 en Cortes de los antiguos reinos de León y Castilla 1861, vol. 1, p. 131.

59. Un ejemplo de la relación entre el honor de la ciudad y el obispado que le correspondía surge de los reclamos de la ciudad de Soria por tener un obispado propio, independiente del de Burgo de Osma. Soria era una ciudad de realengo, mientras Burgo de Osma estaba bajo del dominio temporal del obispo correspondiente a esa sede. Esta diferencia de jurisdicción temporal intentó ser llevada al plano espiritual: una ciudad independiente debía contar con un nuevo obispado con la misma característica. Cfr. Azcona 1960, p. 32.

60. Logan 1978, p. 428. 


\section{3. ¿EL OBISPO ACUÑA COMO OBISPO IDEAL?}

No puede dejar de mencionarse al obispo de Zamora, Antonio de Acuña. Su condición de prelado le otorgó un carácter especial a su participación y a todo el tratamiento que recibió al momento de ser apresado y ejecutado. Suele destacarse que Acuña era un personaje temperamental, ambicioso, amigo de la guerra y poco pendiente de las peticiones espirituales de su tarea. Si se considera la perspectiva de sus enemigos, Acuña habría sido el ejemplo del obispo que se combatía desde las perspectivas reformistas, incluso se lo suele colocar como uno de los últimos ejemplos de esta figura del obispo guerrero. Es decir, su figura podía haber entrado en contradicción con lo demandado por los comuneros en los capítulos citados.

Según pudieron reconstruir los investigadores, Acuña tomó el obispado de Zamora contra la voluntad de los canónigos de la catedral y desde Roma, y luego fue defensor de los bienes de su mitra mediante numerosos pleitos ${ }^{61}$. Asimismo, fue embajador en la Curia Romana de Felipe el Hermoso e intentó volver a serlo con la llegada de Carlos de Gante a la Península ${ }^{62}$. También cumplió otras tareas para la corona, algunas de carácter militar. No tuvo preocupaciones por la residencia y repetidamente se ausentó ${ }^{63}$. Las cartas de fray Antonio de Guevara pueden citarse como ejemplo de ataque a Acuña colocando en el centro las cuestiones espirituales. En una supuesta carta al obispo, dado que siempre se duda el carácter ficticio de los destinatarios de Guevara, declaraba:

Si no quereys imitar a Christo que os crió, imitad a don Luys de Acuña que os engrendró, a cuyas puertas comían cada día muchos pobres y en las vuestras no vemos agora sino jugar y aun reñegar soldados. Hazer de soldados clérigos aun passa, mas de clérigos hazer soldados esto es cosa escandalosa, lo qual, señor, no diremos de vos que lo consentistes sino que lo hizistes, pues truxistes de Çamora a Tordesillas trezientos clérigos de missa, no para confesar a los criados de la reyna, sino para defender aquella villa contra el rey. Por quitaros, señor, de malas lenguas y para más salvación de sus ánimas, sacásteslos de Çamora al principio de la Cuaresma, de manera que como buen pastor y perlado los quitastes de confessar y los occupastes en pelear ${ }^{64}$.

En una supuesta segunda carta, vuelve a enfatizar:

Las casas de los buenos perlados no son sino una escuela de virtuosos, a do nadie ha de saber mentir ni aprender juego, ni ser goloso ni andar dissolutto, ni estar ocioso ni presciarse de hablador, ni ser bullicioso ni aun ambicioso, lo qual no es assi en vuestra casa, a do todos son absolutos y se prescían de dissolutos [...]

61. Fernández Martín 1984. Las biografías de Acuña: Guilarte 1979; Castro Lorenzo 2007.

62. Serio 2007; Fernández de Cordova Miralles 2018.

63. Otros trabajos de interés: Cooper 1996; Fernández Martín 1979, pp. 125-139 y passim; Moreno Vaquerizo 2001.

64. Antonio de Guevara 2004, p. 264. 
Tornaos, pues, señor Obispo, a recoger, arrepentir y a enmendar, porque la lealtad de Castilla no sufre más de un rey ni quiere más de una ley ${ }^{65}$.

Así, el obispo peleaba y hacía pelear a sus clérigos, haciéndoles faltar a sus labores pastorales, vinculadas en este caso a la confesión de Cuaresma. Su casa no estaba organizada como la de un obispo, se pregonaban ambiciones y rebeliones. Aparecía de manera irónica la metáfora del buen pastor, de modo que la crítica refería directamente a su condición de obispo, diferente al tratamiento contra otros comuneros como Juan de Padilla y María Pacheco. Por último, invitaba al obispo a abandonar la revuelta y a ocuparse de tareas relativas a la cura de conciencia: recoger, arrepentir y enmendar ${ }^{66}$.

Esta última carta de Guevara sirve para introducir un punto: la comparación de Acuña con el mítico obispo Oppas o Oppa. Dicho obispo es un personaje cuya existencia histórica ha sido cuestionada, debido a las enormes contradicciones existentes sobre su persona en las crónicas medievales. Oppas habría sido un obispo de la sede hispalense o toledana que habría colaborado con la invasión musulmana y habría sido responsable de algunas matanzas de cristianos ${ }^{67}$. Antonio de Guevara afirmaba que había visto a Antonio de Acuña en la célebre mediación de Villabragima acompañado de tantos comuneros y cargado de tantos negocios, estuve conmigo dubdando si lo que veýa era sueño o si avía el obispo don Orpas ressucitado ${ }^{68}$. En el mismo sentido, la crónica anónima de un supuesto criado de Isabel la Católica, comentaba la huida de Acuña Otros huyeron, como el segundo don Olpas, que se escapó huyendo ${ }^{69}$. De esta manera, Acuña entraba entre los míticos traidores de la historia de España ${ }^{70}$.

Por su parte, el humanista Juan Maldonado en su De motu Hispaniae realizó una de las más detalladas narraciones sobre los comuneros, con un alto contenido literario $^{71}$. Asimismo, su Pastor Bonus es una de las obras sobre el ideal de obispo en el siglo XVI en la Península ${ }^{72}$. Su caracterización del obispo Acuña, quizás la más extensa de las que se han conservado, destacaba muy bien esta imagen del obispo guerrero, con grandes capacidades personales para luchar, no para ser pastor de almas. La vida de Maldonado en Burgos no sólo lo hizo conocedor de Acuña, ciudad de donde el padre de éste, Luis de Acuña, había sido obispo, sino también muestra una importante relación con su hermano, el corregidor Diego de Osorio. Su obra Hispaniola, fechada en 1535, está directamente dedicada a este personaje bajo la siguiente advertencia: Lege interim ludicra, seria, ni fuerint per

65. Antonio de Guevara 2004, pp. 271 y 274.

66. Sobre Antonio de Guevara: Redondo, 1976.

67. Sobre este personaje: Fernández Conde 2008, pp. 30-31; Bronisch 2011.

68. Antonio de Guevara 2004, p. 271.

69. Relación del discurso de las Comunidades 2003, p. 184.

70. Sobre la traición en la historia de España: Padin Portela 2019.

71. Sobre De motu Hispaniae: García García 1983a, pp. 31-67; Pérez-Romero 2005, pp. 131-169.

72. Obra con fecha de Burgos, 1529, hay edición moderna en: Spanish humanism in the verge of the picaresque 2009, pp. 104-217. Sobre esta obra: Bataillon 1983, pp. 328-339; García García 1983b. 
communitates quas dicunt intercepta, iam subsequentur ${ }^{73}$. La comparación se repite en su relato de las Comunidades ${ }^{74}$. Además, esta contraposición entre Diego de Osorio y su hermano obispo tiene ecos en la obra de Gonzalo Fernández de Oviedo. En sus Batallas y Quinquagenas comparaba a los dos hermanos, llamando como Alonso a Antonio:

dos hermanos hayan seydo tan diferentes en méritos e obras: el uno loco, el otro cuerdo; el uno soberbio, fecho un lucifer; el otro un ángel manso e con toda la bondad del mundo; el uno desleal e deshonesto, el otro leal y honesto; el uno cruel e malo, el otro piadoso e bueno, como nos lo han mostrado el obispo de Zamora, don Alonso de Acuña el comunero, e este su hermano, don Diego de Osorio ${ }^{75}$.

Como se ve, la contraposición era muy clara y los atributos a cada uno merecen destacarse. Diego como ángel, su hermano obispo como soberbio y luciferino, además de una lista de virtudes y vicios para cada uno. A pesar de estos datos y la contradicción que pueda evidenciarse, elementos propios del ideal de obispo que circulaba en la Cristiandad de aquellos años pueden percibirse en la construcción que Maldonado realizaba de Acuña, en los discursos que le atribuía. Si bien podría acusarse que se trataba de una representación literaria, es interesante que los valores que ponía en juego el obispo con sus seguidores, siempre en el relato de Maldonado, tenían un fuerte contenido religioso, propio de un pastor de almas y cercano al sermón, y no una arenga propia de un guerrero. Dentro del marco del ideal de obispo se presentaban algunos elementos. Acuña estaba sacrificándose por su pueblo, rechazando enriquecerse y cuidando los intereses o conveniencias de los débiles o pequeños (tenuium commoditatibus) ${ }^{76}$. Aquí sería la imagen del

73. Juan Maldonado 1983, p. 56. Sobre Diego de Osorio en la revuelta: Guilarte 1979, pp. 100106; Castro Lorenzo 2007, pp. 80-81. Diego de Osorio, como corregidor de Córdoba, aparentemente inspiró la idea de agrupar a las ciudades andaluzas como leales al rey, según se desprende del proceso de residencia que sufrió posteriormente, publicado fragmentariamente en: Danvila y Collado 18971900, vol. V, pp. 473-478.

74. Juan Maldonado 1991, pp. 260 y 262.

75. Gonzalo Fernández de Oviedo 2000, T. III, p. 249, trata sobre Diego de Osorio en pp. 249253. Maldonado también realizaba una comparación similar entre ambos hermanos comentando: "Antonius Acunna Iacobi Ossorii, quem Burgis praefectum primo diximus creatum, germanus est frater; tanta tamen vitae morumque disparilitas duos inter hos fratres inesse dignoscitur, ut monstro prope simile sit ex eodem utero tam varios dissonosque prodiisse mores", Juan Maldonado 1991, pp. 260261.Versión castellana: "Antonio de Acuña es hermano de padre y madre de Diego Osorio, de quien ya hemos dicho que fue nombrado corregidor en Burgos en un primer momento. Sin embargo es sabido que la diferencia de vida y costumbres entre ambos hermanos es tan grande que parece casi un prodigio que de un mismo vientre hayan salido caracteres tan distintos y discordantes", Ibid., p. 261.

76. "Haud ignorare vos puto, mei cives et vere commilitones, nulla me divitiarum aut honorum cupiditate ductum studia populororum comprobasse eorumque conatus omni cura ad iuvandos instituisse, qui probe sciatis habere me pontificatum, qui possit adolescentis, nedum mei iam senescentis, quamlibet concupiscentiam explere. Quadraginta milia ducatorum aureorum mihi recondebantur in arca, cum ii motus praeclari sunt excitati, quos quidem omnes in hoc maxime servabam, ut pios in usus insumerem; nunc defluxisse penitus omnes ac disperiisse, quo vobis vestrisque commoditatibus, libertati praesertim omnium inservirem optime norunt ii, qui mea vectigalia procurant quique meo sun aerario praepositi. Libertatem certe nullam aut inmmunitatem mihu paro, satis me meus ordo, 
obispo como "padre de los pobres", garantizando su alimento y su bienestar" Además, el obispo no sólo debía mandar e ir por delante de sus ovejas, sino también dar la vida por ellas, elemento claro de un buen pastor ${ }^{78}$. Como diría Bernardo de Claraval, el episcopado era un deber no un señorío, ministerium no dominium ${ }^{79}$. Por último, puede percibirse un claro discurso de servicio en las palabras atribuidas a Acuña, aspecto fundamental en la tradición episcopal según lo ha expuesto Yves Congar respecto de la formula praeesse est prodesse $e^{80}$.

A su vez, aspectos relativos al ideal de obispo aparecen en las mismas palabras de Acuña que se han conservado. Es conocido su intento de hacerse con el arzobispado de Toledo, nunca aclarado si en términos de administrador o como arzobispo. La junta lo había enviado, luego de la muerte del joven arzobispo Guillermo de Croy, para hacerse con el control de todo lo relativo al poder del arzobispado. Bajo esta razón Acuña modificó su rumbo y entró en Toledo a fines de marzo de 1521. Según la documentación que se consulte, puede hacerse una interpretación minimalista - buscaba hacerse de las rentas del arzobispado- o una maximalista -quería ser nombrado arzobispo por voluntad popular y luego ser ratificado por los poderes eclesiásticos y monárquicos. Al margen de estas discusiones, la carta enviada por Acuña a la ciudad de Alcalá de Henares, donde se relataba su llegada a Toledo, afirmaba: me llevaron a la iglesia catedral de la dicha cibdad y me

mea infula, meus praesulatus reddit immunem. Nihil me regum decreta perstringunt, nihil novae commovent exactiones. Num igitur famam aut nobilitatem quaero? Minime; satis abunde gloriae, famae nobilitatisque vel umbra meorum mihi maiorum conciliat. Quid igitur dicetis vos tot sudoribus, tot vigiliis, tot tantisque rei familiaris iacturis ac offensis, tot vitae discriminibus, tot procerum ac magnatum ultro arcessitis inimicitiis, qui ad fossam, quod aiunt, me nunquam non persequentur, quaerito? Mihi nempe nihil; vobis omnis mea cura invigilat, tenuium commoditatibus inservio. Maximas mihi divitias, celebre nomen, famam perennem animique veram quietem optime cumulateque parasse me quidem putabo, cum tributis ac immodicis plebeculam exactionibus paulisper allevaro, cum pauperculis modum compilandis imponere magistratus coegero, cum vel limites certos praescripsero, quos vectigalium redemptoribus fas praeterire non sit. Quae maior gloria, quod amplius patrimonium, quae fama perennior quam civibus meis todo captu, toto denique nixu profuisse, quam usui rei publicae maximo fuisse, quam leges, quae miseram plebeculam absorbent, abrogasse? Quid igitur restat, viri fortissimi, nisi vos ut aliquando tandem expergiscamini, vestrum ducem, qui nihil sibi quaerit, qui strenue vobis operam navare vitam simul etiam, si detur, impendere studet, sequamini, opibus armatisque militibus iuvetis? Haud utique vobis ipse deerit, si vobis ipsi non defeuritis. An divinum auxilium tam piae causae defuturum existimabitis? Nulli vos quidem vim facere, sed a vi duraque tyrannide, quam in vos proceres regiique magistratus et publicani quidem immites exercent, vindicare molimini, famen declinare, vestra tuendo non aliena ereptum eundo parati. Num ego sacerdos causam omnino probarem, quam Deo crederem non ese pergratam? Maximo sit vobis argumento causam esse vestram piissimam pontificem, cui quae pietati minus conducunt arma sunt interdicta, bello tam ardenter implicari. Plura dicerem, si longis exhortationibus indigere nunc crederem, si res me non ipsa tacente clamitaret. Victoria certe propediem insignis faciet manifestum utram magis causam probarit Christous". Juan Maldonado 1991, pp. 346 y 348.

77. Esta imagen aparece repetidamente en la tradición, para algunos casos del siglo XVI cfr. Tellechea Idígoras 1963, pp. 56-57, 101, 191-193 y 206. Recuérdese por ejemplo la contraposición de Antonio de Acuña con su padre que hacía Antonio de Guevara, mencionando como Luis de Acuña alimentaba a los pobres.

78. Sobre esta idea: Ibid., pp. 127-128.

79. Cfr. Congar 1966b, p. 87.

80. Congar 1966a. 
hicieron asentar en la silla arzobispal ${ }^{81}$. Luego agregaba: Creo que todo procede de Dios, al cual plega encaminar en todo como sea servido y como nuestro santo propósito vaya adelante como cosa tan santa ${ }^{82}$.

Como contraparte, la acusación del fiscal Pero Ruiz, en el proceso contra el obispo, con fecha del 16 de abril de 1524, recogía una gran cantidad de delitos realizados bajo la órbita de Acuña, según la cual respecto del arzobispado dixo públicamente que iba a ser arzobispo de Toledo ${ }^{83}$. La diferencia entre ambas versiones es clara: un Acuña que llegaba a Toledo y era nombrado por aclamación, y uno que antes de dirigirse hacia allí ya planeaba quedarse con la mitra. Aquello que pudiera ser una estrategia judicial de inocencia o culpabilidad, posee también un sentido teológico pastoral: según el ideario de Gregorio Magno ambicionar la mitra incapacitaba al interesado a tenerla ${ }^{84}$. Asimismo, siguiendo a Gregorio, de enorme influencia para la construcción de la disciplina interna de la propia Iglesia, si le era ofrecido el episcopado, se debía obedecer y aceptarlo ${ }^{85}$. De este modo, confrontando estos dos documentos, no sólo se salvaba Acuña de las acusaciones -fue una defensa común de muchos ex comuneros de prestigio afirmar que fueron obligados por la plebe a realizar esos actos- sino también se presentaba en coincidencia con toda una tradición pastoral, donde las ambiciones y voluntades personales debían dejarse de lado. Este último aspecto cobra particular importancia si se considera al interlocutor de la carta, el ambiente reformista de Alcalá, con su Universidad de fuerte compromiso comunero. Sin poder mostrar que se trataba de un obispo que seguía los idearios pastorales -su carrera episcopal había sido muy similar a la que los mismos comuneros denunciaban- puede desatacarse su preocupación por presentarse relacionado con alguno de esos tópicos.

\section{REFLEXIONES FINALES: OBISPADO E IGLESIA LOCAL}

Hasta aquí se han reconstruido las diferentes posiciones de los comuneros respecto del episcopado, mostrando el permanente diálogo con las corrientes de la época, combinando intereses ciudadanos con intereses pastorales y con un énfasis por la iglesia local a partir de la necesidad de residencia. En este marco existen elementos todavía por abordarse. William Christian Jr. destacaba la búsqueda de localizar lo sagrado entre los fieles del catolicismo temprano moderno. En el contexto de volver local lo numinoso, con novecientas capillas para quinientas aldeas

81. Carta a Alcalá de Henares, 29 de marzo de 1521, reproducida como apéndice en: Guilarte 1979, p. 223.

82. Idem.

83. “Acusación del fiscal Pero Ruiz en el proceso contra el obispo de Zamora, don Antonio de Acuña”, reproducida como apéndice en: Fernández Martín 1979, pp. 498-50, aquí 502.

84. Cfr. Jaeger 1985, pp. 56-58. Tomas de Aquino comentaba que el episcopado no podía apetecerse porque nadie debe pensar que está capacitado para tan alta función, cfr. Commentaria in I ad Timotheum 3, 2.

85. Cfr. Lemesle 2015, pp. 94-96. Puede destacarse, a nivel europeo, que la Regula Pastoralis de Gregorio Magno tuvo ediciones al menos en 1506, 1512 y 1516, cfr. Broutin 1953, p. 12. 
recogidas por este autor, ubica de modo más adecuado la pretensión comunera, y de buena parte del catolicismo del siglo XVI, de reforzar las iglesias locales, comenzando por la residencia de sus obispos, ocupados en las tareas pastorales ${ }^{86}$. Puede añadirse, a su vez, el localismo en términos de lo que suele llamarse "patriotismo local", propio de las aldeas, ciudades o regiones ${ }^{87}$.

En este punto, resta por estudiarse de manera más amplia el impacto de cierto pensamiento diocesano presente entre los comuneros. Puede referirse aquí la pretensión, expuesta en la llamada "Constitución de Ávila", de reorganizar la representación de Cortes por cada obispado y arzobispado en los lugares bajo control real, en lugar de por ciudad, incorporando clérigos y grupos populares entre los representantes:

La otra con que cada cuando se hubieren de hacer Córtes, los logares realengos de cada un obispado é arzobispado elijan dos procuradores que vayan á la Cortes, el uno de los hidalgos y el otro de los labradores, é questos no puedan haber merced ninguna ni el Rey gela pueda dar, é que cada uno de los obispados elijan un clérigo que vaya á las Córtes, é de los caballeros elijan dos caballeros, é de las órdenes de los oservantes dos frayles, el uno francisco y el otro dominicio, é que de los obispados del reino de Galicia no hay más de dos procurados porque son pequeños ${ }^{88}$.

Este mismo criterio, fue propuesto por los comuneros para la reforma del Consejo Real, pidiendo que en el Consejo haya de haber tantos oidores como obispados haya en estos reinos de Castilla, en esta manera: que en cada un obispado elijan tres letrados de ciencia é conciencia é edad de cada cuarenta años ${ }^{89}$. La importancia del estamento eclesiástico que se desprende de estos capítulos fue explicada por la gran participación clerical en la revuelta, afirmando la diócesis será así el modelo de la reorganización administrativa territorial pretendida por los comuneros $^{90}$. Otros capítulos compartían un trasfondo de localismo eclesiástico respecto de la solicitud que los beneficios eclesiásticos fuesen provistos a personas nacidas y bautizados dentro de los límites de los obispados y arzobispados, ya no sólo que no fuesen extranjeros ${ }^{91}$. Este localismo en los beneficios abría directamente conflictos en los pueblos, oponiéndose los vecinos a que se nombrase un

86. Christian 1991. Destacaba también la particularidad del culto, con una exuberancia en las prácticas, a nivel de cada parroquia: Chiffoleau 2011, pp. 68-70.

87. Cfr. Bercé 2013, p. 47.

88. Capítulo 3 de "Capítulos de lo que ordenaban de pedir los de la Junta", reproducidos como apéndice en Jerez 2007, p. 599.

89. Capítulo 2 de "Capítulos de lo que ordenaban de pedir los de la Junta", reproducidos como apéndice en Jerez 2007, p. 599. Sobre el Consejo Real en la acción y el pensamiento comunero: Ibid., pp. 360-362; Pérez 1999, pp. 187 y ss.; Bermejo Cabero 1973; Diago Hernando 2001, pp. 181-183.

90. Beneyto 1958, p. 373. José Luis Bermejo Cabrero distinguía entre una impronta local inicial en la revuelta, para una disminución del localismo y la base comunal en los capítulos comuneros, cfr. Bermejo Cabrero 1988 p. 247.

91. Capítulo 7 de "Capítulos de lo que ordenaban de pedir los de la Junta", reproducidos como apéndice en Jerez 2007, p. 600. Sobre los beneficios eclesiásticos: Barrio Gozalo 2010b. 
clérigo "romano" para determinado beneficio: se exigía prioridad a los hijos naturales del pueblo ${ }^{92}$. El rechazo de esta posición podía generar reacciones violentas, como se recoge en casos de Tierra de Campos en plena revuelta ${ }^{93}$. La contracara de estas quejas era otro aspecto que podía producir graves problemas para el buen comportamiento del clero, que era el de la llamada patrimonialización y endogamia de los beneficios, en especial en los cargos capitulares ${ }^{94}$.

No obstante, luego de esta exposición, una consigna se mantiene: ¿qué se estaba recuperando en estos conflictos? ¿Existe relación entre el énfasis diocesano respecto de la pastoral con este modelo de representación? El discurso de Acuña ya mostraba la fácil traducción de ciertos topoi religiosos o eclesiásticos hacia la política ${ }^{95}$. La posición conciliarista entre los castellanos y españoles en la época de Carlos V es difícil de estudiar debido a la evolución de los enfrentamientos del emperador con el papado. En muchas ocasiones, se trataba de una carta disponible entre los imperiales para generar oposición a Roma, lejos de una visión conciliar respecto de la Iglesia Universal. No obstante, como se ha señalado, las ideas conciliaristas presentaban atractivo para el clero castellano en los años cercanos al inicio del concilio de Trento, en especial vinculadas a lo que genéricamente puede llamarse episcopalismo ${ }^{96}$. Cabe destacar que se ha sugerido que el fortalecimiento de la autoridad episcopal fue el punto básico para toda reforma para los representantes españoles en el concilio ${ }^{97}$.

Como se ha citado, John B. Owens se ha ocupado de otorgar un rol central a una influencia conciliar entre las ideas comuneras, en especial de los sectores intelectuales asociados a ella vinculados con la Universidad de Salamanca, de la cual el célebre Juan de Segovia fue representante en el Concilio de Basilea a partir de 1433 y cuya historia de dicho concilio se conservó en la Universidad ${ }^{98}$. Si bien no puede proponerse una respuesta contundente en este punto, resta señalar la familiaridad en los acentos, la dimensión local y diocesana para ocuparse de los fieles, al igual que para construir los organismos de gobierno del reino ${ }^{99}$. De una u otra manera, no dejan de poder ubicarse las aproximaciones comuneras en los debates sobre el destino de la Iglesia en el siglo XVI.

92. La idea de lo local debe ser aclarada. Como ha mostrado Helen Nader, lo local se encontraba en disputas entre las ciudades castellanas y las villas que formaban parte de ellas que pretendieron obtener un gobierno local propio y autónomo de las ciudades. La monarquía en muchas oportunidades se apoyó en las villas frente a los poderes de las ciudades, cfr. Nader 1990. No obstante, según la autora se trataba en todos los casos de poderes urbanos, de diferentes características y tamaños.

93. Fernández Martín 1979, pp. 52-53.

94. Morgado García 2000, pp. 62-63.

95. Un enfoque fundamental en este sentido: Iona-Prat 2016.

96. Tubau 2017.

97. García Guerrero 1943, p. 17.

98. Owens 2005, pp. 102-113.

99. Sobre el destino de esta idea de organización diocesana en los capítulos posteriores: Jerez 2007, pp. 332-333. 


\section{BibliografíA UTILIZADA}

Almeida do Rolo, Raul de (1965), L'Evêque de la Réforme Tridentine sa mission Pastorale d'après le Vénérable Barthélemy des Martyrs, Lisboa.

Alonso Acero, Beatriz (2006), Cisneros y la conquista española del norte de África: cruzada, política y arte de la guerra, Madrid.

Arranz Guzmán, Ana (1990), "La imagen del pontificado en Castilla a través de los Cuadernos de Cortes", Hispania Sacra, Vol. 42 n 86, pp. 721-760.

Arranz Guzmán, Ana (2014), "Justificación ideológica y participación armada del episcopado castellano en la Reconquista (1295-1360)", en Martínez Ruiz, Enrique y Cantera Montenegro, Jesús (dirs.) Perspectivas y novedades de la Historia Militar. Una aproximación global, Madrid, 2 vols., vol. 1, pp. 313-334.

Azcona, Tarsicio de (1958), "El tipo ideal de obispo en la Iglesia Española antes de la rebelión luterana", Hispania Sacra, 11, pp. 17-44.

Azcona, Tarsicio de (1960), La elección y reforma del episcopado español en tiempos de los Reyes Católicos, Madrid.

Azcona, Tarsicio de (1980), "Reforma del episcopado y del clero de España en tiempo de los Reyes Católicos y de Carlos V (1475-1558), en García Villoslada, Ricardo (dir.) Historia de la Iglesia en España- III. La Iglesia en la España de los siglos XV y XVI, vol. 1 segunda parte, Madrid, pp. 113-210.

Azcona, Tarsicio de (1986), "El hecho episcopal hispánico en tiempo de Carlos V (1516-1558)" en Revuelta Sañudo, Manuel; Morón Arroyo, Ciriaco (eds.) El erasmismo en España: ponencias del coloquio celebrado en la Biblioteca de Menéndez Pelayo del 10 al 14 de junio de 1985, Santander, pp. 265-288.

Bataillon, Marcel (1983), Erasmo y España Erasmo y España. Estudios sobre la historia espiritual del siglo XVI, Madrid.

Barrio Gozalo, Maximiliano (2000), Los obispos de Castilla y León durante el Antiguo Régimen (1556-1834): estudio socioeconómico, Valladolid.

Barrio Gozalo, Maximiliano (2004), El Real Patronato y los obispos españoles del Antiguo Régimen (1556-1834), Madrid.

Barrio Gozalo, Maximiliano (2010a), El clero en la España Moderna, Córdoba.

Barrio Gozalo, Maximiliano (2010b), El sistema beneficial de la Iglesia Española en el Antiguo Régimen (1475-1834), Alicante.

Bédouelle, Guy (2005), La Reforma del catolicismo (1480-1620), Madrid.

Belmonte Díaz, José (1986), Los comuneros de la Santa Junta: la constitución de Ávila, Ávila.

Beneyto, Juan (1958), Historia de la Administración española e hispanoamericana, Madrid.

Bercé, Yves-Marie (2013), Révoltes et révolutions dans l'Europe moderne, Paris.

Bermejo Cabero, José Luis (1973), "La gobernación del Reino en las comunidades de Castilla”, Hispania, n 124, pp. 249-264.

Bermejo Cabrero, José Luis (1988), "Las Comunidades de Castilla (1520-1521) ¿Revuelta o revolución?” en Mohaupt, Heinz (ed.) Revolution, Reform, Res- 
tauration. Formen der Veränderung von Recht und Gesellschaft, Frankfurt am Main, pp. 235-250.

Bronisch, Alexander Pierre (2011), "Precisiones sobre algunas informaciones en la 'Crónica de Alfonso III'”, Edad Media. Revista de Historia, n 12, pp. 35-66.

Broutin, Paul (1953), L'evêque dans la tradition pastorale du XVIe siècle d'après “Das bishofsideal der katholischen Reformation de Hubert Jedin”, Lovaina.

Capelli, Guido (2012), “"Corpus est res publica» La struttura della comunità secondo l'umaneismo politico" en Geri, Lorenzo (coord.) Principi prima del Principe, Lorenzo Geri (coord.), Roma, pp. 59-73.

Cartelon, Keneth (2001), Bishops and Reform in the English Church, 1520-1559, Suffolk.

Castro Lorenzo, José de (2007), Don Antonio de Acuña y su época, Valladolid.

Christian, William Jr. (1991), Religiosidad Local en la España de Felipe II, Madrid.

Coleman, David (2003), Creating Christian Granada: Society \& religious culture in an Old-World Frontier City, 1492-1600, Ithaca.

Congar, Yves (1966a), "Algunas expresiones tradicionales del servicio cristiano" en Congar, Yves y Dupuy, Bernard-Dominique. El episcopado y la Iglesia Universal, Barcelona, pp. 97-126.

Congar, Yves (1966b), "La jerarquía como servicio según el Nuevo Testamento y los documentos de la Tradición" en Congar, Yves y Dupuy, Bernard-Dominique (dirs.) El episcopado y la Iglesia Universal, Barcelona, pp. 67-96.

Congar, Yves (1968), L'ecclésiologie du haut Moyen-Age. De Saint Grégoire le Grand à la désunion entre Byzance et Rome, Paris.

Chiffoleau, Jacques (2011), La religion flamboyante. France (1320-1520), Paris.

Cooper, Edward (1996), "La revuelta de las Comunidades de Castilla. Una visión desde la sacristía", Hispania, vol. 56/2 n 193, pp. 467-495.

Cortes de los antiguos reinos de León y Castilla (1861-1903), Madrid, 5 vols.

Danvila y Collado, Manuel (1897-1900), Historia crítica y documentada de las Comunidades de Castilla, Madrid, 6 vols.

D’Avenia, Fabrizio (2015), La Chiesa del re. Monarchia e Papato nella Sicilia spagnola (secc. XVI-XVII), Roma.

De Boer, Wietse (2001), The Conquest of the Soul: Confessions, Discipline, and Public Order in Counter-Reformation Milan, Leiden.

Delumeau, Jean (1957 y 1959), Vie économique et sociale de Rome dans la seconde moitié du XVIe siècle, Roma, 2 vols.

Delumeau, Jean (1973), El Catolicismo de Lutero a Voltaire, traducción de Miguel Candel, Barcelona.

Diago Hernando, Máximo (2001), Le comunidades di Castiglia (1520-1521). Una rivolta urbana contro la monarchia degli Asburgo, Milán.

Diago Hernando, Máximo (2007), "El factor religioso en el conflicto de las Comunidades de Castilla (1520-1521). El papel del clero", Hispania Sacra, vol. $59, \mathrm{n}^{\circ} 119$, pp. 85-140. 
Fernández Albaladejo, Pablo (1992), Fragmentos de monarquía. Trabajos de historia política, Madrid.

Fernández Conde, Francisco Javier (2008), La religiosidad medieval en España. Alta Edad Media, Gijón.

Fernández de Cordova Miralles, Álvaro (2018), “Antonio de Acuña antes de las Comunidades, su embajada en Roma al servicio de Felipe el Hermoso", en Szaszdi León-Borja, István (coord.) Iglesia, eclesiásticos y revolución comunera, Valladolid, pp. 71-121.

Gonzalo Fernández de Oviedo (2000), Batallas y Quinquagenas, transcripción de José Amador de los Rios y Padilla, prólogo y edición de Juan Pérez de Tudela y Bueso, Madrid, Tomo III.

Fernández Martín, Luis (1979), El movimiento comunero en los pueblos de Tierra de Campos, León.

Fernández Martín, Luis (1984), "El obispo comunero Don Antonio de Acuña, defensor de los bienes de la mitra zamorana (1509-1518)", Hispania Sacra, vol. $36 \mathrm{n}^{\circ} 74$, pp. 485-508.

Fernández Terricabras, Ignasi (2001), Philippe II et la Contre-Réforme. L'Église espagnole à l'heure du Concile de Trente, Paris.

Fleming, Gillian Beatrice (2018), "A blacklisted bishop of the Comunero uprising: the case of Diego Ramírez de Villaescusa”, en Szaszdi León-Borja, István (coord.) Iglesia, eclesiásticos y revolución comunera, Valladolid, pp. 123-149.

Forrestal, Alison (2004), Fathers, pastors and kings: Visions of episcopacy in seventeenth-century France, Manchester.

García García, Heliodoro (1983a), El pensamiento comunero y erasmista de Juan Maldonado, Madrid.

García García, Heliodoro (1983b), “El reformismo del 'Pastor Bonus' de Juan Maldonado", Hispania, vol. 35 n 71, pp. 193-218.

García Guerrero, Francisco (1943), El decreto de residencia de los obispos en la tercera asamblea del concilio tridentino. Especial intervención de los prelados españoles, Cádiz.

García Hernán, Enrique (2006), “Capellanes militares y Reforma Católica”, en García Hernán, Enrique; Maffi, Davide (coords.) Guerra y sociedad en la monarquía hispánica: política, estrategia y cultura en la Europa moderna (1500-1700), Madrid, 2 vols, vol. 2 pp. 709-742.

García Oro, José (1992), El Cardenal Cisneros. Vida y empresas, Madrid, 2 Vols.

Gleason, Elisabeth G. (1993), Gasparo Contarini: Venice, Rome, and Reform, Berkeley.

González Faus, José I. (1992), «Ningún obispo impuesto» (San Celestino, Papa). Las elecciones episcopales en la historia de la Iglesia, Santander.

González Montes, Adolfo (2008), Imagen de la Iglesia. Eclesiología en perspectiva ecuménica, Madrid.

Goñi Gaztambide, José (1958), Historia de la Bula de Cruzada en España, Vitoria. Antonio de Guevara (2004), Obras Completas III. Epístolas Familiares, edición Emilio Blanco, Madrid. 
Guilarte, Alfonso M. (1979), El obispo Acuña: Historia de un comunero, Valladolid.

Gutiérrez, Constancio (1951), Españoles en Trento, Valladolid.

Harris, A. Katie (2007), From Muslim to Christian Granada: Inventing a City's Past in Early Modern Spain, Baltimore.

Hermann, Christian (1976), "L’Église selon les Cortes de Castille: 1476-1598", Hispania Sacra, Vol. 26 n 53-54, pp. 201-235.

Hermann, Christian (1986), "Naturales y forasteros. Les exclusives d'accès aux bénéfices de l'église dans l'Espagne Moderne" en Les sociétés fermées dans le monde ibérique (XIVe-XVIIIe s.). Définitions et problématique, Paris, pp. 189-201.

Hill, Christopher (1956), Economic Problems of the Church from Archbishop Whitgift to the Long Parliament, Oxford.

Iannuzzi, Isabella (2009), El poder de la palabra en el siglo XV: Hernando de Talavera, Salamanca.

Iogna-Prat, Dominique (2016), Cité de Dieu, Cité des hommes. L'Église et l'architecture de la société, Paris.

Jaeger, C. Stephen (1985), The origins of courtliness: Civilizing trends and the formation of courtly ideals 939-1210, Philadelphia.

Jedin, Hubert (1965), El concilio de Trento en su última etapa: crisis y conclusión, Barcelona.

Jerez, José Joaquín (2007), Pensamiento político y reforma institucional durante la guerra de las Comunidades de Castilla (1520-1521), Madrid.

Kantorowicz, Ernst H. (2012), Los dos cuerpos del rey. Un estudio de teología política medieval, Madrid.

Kung, Hans (1968), La Iglesia, Barcelona.

Lappin, Anthony John; Balzamo, Elena (eds.) (2018), Dominus Episcopus: Medieval bishops between Diocese and Court, Estocolmo.

Lemesle, Bruno (2015), Le gouvernement des évêques. La charge pastorale au milieu du Moyen Âge, Rennes.

Logan, Oliver (1978), "The ideal of the Bishop and the Venetian Patriciate: c. 1430-1630", The Journal of Ecclesiastical History, n²9, pp. 415-450.

López Martín, Juan (1971), La imagen del obispo en el pensamiento teológicopastoral de don Pedro Guerrero en Trento, Roma.

Lozano Navarro, Julián J. (2005), La compañía de Jesús y el poder en la España de los Austrias, Madrid.

Lubac, Henri de (2009), Corpus mysticum. L'Eucharistie et l'Église au Moyen Âge, Paris.

Juan Maldonado (1983), Hispaniola/La española, edición, introducción, traducción y notas de Ma. Ángeles Durán Ramas, Barcelona.

Juan Maldonado (1991), De motu Hispaniae/ El levantamiento de España, traducción, notas e introducción de Ma. Ángeles Durán Ramas, Madrid. 
Maravall, José Antonio (1973), “La idea de cuerpo místico en España antes de Erasmo", en Maravall, José Antonio Estudios de Historia del pensamiento español, Madrid, pp. 191-213.

Marín Ocete, Antonio (1970), El arzobispo don Pedro Guerrero y la política conciliar española en el siglo XVI, Madrid, 2 vols.

Martínez Ruiz, Enrique. "El ocaso de los clérigos guerreros en Castilla", en Szaszdi León-Borja, István (coord.) Iglesia, eclesiásticos y revolución comunera, Valladolid, pp. 42-67.

Martínez Soria, Carlos Julián; Millán Martínez, Juan Manuel (coords.) (2009) Diego Ramírez de Villaescusa: Obispo y mecenas, Cuenca.

Mazín, Óscar (2012), "Representaciones del poder episcopal en Nueva España (siglos XVII y primera mitad del XVIII)", en Mazín, Oscar (ed.) Las representaciones del poder en las sociedades hispánicas, México, pp. 373-401.

Morán Martín, Remedios (2018), "Guerra de las Comunidades y beneficios eclesiásticos. El detonante de un problema enquistado” en Szaszdi León-Borja, István (coord.) Iglesia, eclesiásticos y revolución comunera, Valladolid, pp. 267-281.

Moreno Vaquerizo, Antonio (2001), “El milenio en Alcalá. Sobre la mesiánica entrada del obispo Acuña, caudillo comunero, en la villa complutense", en VII Encuentro de Historiadores del Valle de Henares: libro de Actas, Guadalajara, pp. 161-176.

Morgado García, Arturo (2000), Ser clérigo en la España del Antiguo Régimen, Cádiz.

Nader, Helen (1990), Liberty in Absolutist Spain: The Habsburg sale of towns, 1516-1700, Baltimore.

Nalle, Sara T (1992), God in La Mancha. Religious Reform and the people of Cuenca, 1500-1650, Baltimore.

Nieto, José Constantino (1997), El Renacimiento y la otra España. Visión Cultural Socioespiritual, Ginebra.

Nieto Soria, José Manuel (1993), Iglesia y génesis del Estado Moderno en Castilla (1369-1480), Madrid.

Nieto Soria, José Manuel (1997), “Origen divino, espíritu laico y poder real en la Castilla del Siglo XIII", Anuario de Estudios Medievales, n 27, pp.43-101.

O'Banion, Patrick J. (2010), "For the defense of the faith? The Crusading Indulgence in Early Modern Spain", Archive für Reformationsgeschichte, $\mathrm{n}^{\circ} 101$, pp. 164-185.

Olmedo, Félix G. (1944), Diego Ramírez de Villaescusa (1459-1537), fundador del Colegio de Cuenca y autor de los Cuatro Diálogos sobre la muerte del príncipe Juan, Madrid.

Owens, John B. (2005), "By my Absolute Royal Authority”: Justice and the Castilian Commonwealth at the beginning of the First Global Age, New York.

Padin Portela, Bruno (2019), La traición en la historia de España, Madrid. 
Palazzo, Eric (2004), "La liturgie épiscopale au Moyen Âge et sa signification théologique et politique" en Aurell, Martín; García de la Borbolla, Ángeles (eds.) La imagen del obispo hispano en la Edad Media, Pamplona, pp. 61-73.

Parsons, Jotham (2004), The Church in the Republic: Gallicanism \& Political Ideology in Renaissance France, Washington.

Pascoe, Louis B., S. J. (2005), Church and Reform: Bishops, theologians, and canon lawyers in the thought of Pierrre D'Ailly (1351-1420), Leiden.

Pastore, Stefania (2010), Una Herejía española. Conversos alumbrados e Inquisición, Madrid.

Peralta, Ramón (2010), La Ley Perpetua de la Junta de Ávila (1520). Fundamentos de la democracia castellana, Madrid.

Pérez, Joseph (1999), La revolución de las comunidades de Castilla (1520-1521), Madrid.

Pérez, Joseph (2014), Cisneros, el cardenal de España, Madrid.

Pérez-Romero, Antonio (2005), The subversive tradition in Spanish Renaissance Writing, Lewisburg.

Perrone, Sean T. (2008), Charles V and the Castilian Assembly of the Clergy: Negotiations for the Ecclesiastical Subsidy, Leiden.

Peyrous, Bernard (1995), La Réforme catholique à Bordeaux (1600-1719), Burdeos, 2 vols.

Pié-Ninot, Salvador (2009) Eclesiología. La sacramentalidad de la comunidad cristiana, Salamanca.

Pierre, Benoist (2013), La monarchie ecclésiale. Le clergé de cour en France à l'époque moderne, Seyssel.

Pietschmann, Horst (1992), “El problema del 'nacionalismo’ en España en la Edad Moderna. La resistencia de Castilla contra el emperador Carlos V”, Hispania, Vol. 52/1, n 180 , pp. 83-103.

Po-Chia Hsia, Ronald (2010), El mundo de la renovación católica, 1540-1770, Madrid.

Rawlings, Helen E. (1987), "The secularism of Castilian Episcopal Office under the Habsburgs, c. 1516-1700”, Journal of Ecclesiastical History, vol. 38, ${ }^{\circ} 1$, pp. 53-79.

Redondo, Augustin (1976), Antonio de Guevara (1480?-1545) et l'Espagne de son temps. De la carrière officielle aux auvres politico-morales, Ginebra.

Relación del discurso de las Comunidades (2003), edición de Ana Díaz Medina, Valladolid.

Rouco Varela, Antonio María (2001), Estado e Iglesia en la España del siglo XVI, Madrid.

Santiso, Anthony (2014), Une foi composite. Le Diálogo de la doctrina cristiana de Juan de Valdés, Paris.

Serio, Alessandro (2007), "Una representación de la crisis de la unión dinástica. Los cargos diplomáticos en Roma de Francisco de Rojas y Antonio de Acuña (1501-1507)", Cuadernos de Historia Moderna, n 32, pp. 13-29. 
Sola Colomer, Xavier (2008), La reforma católica a la muntanya catalana a través de les visites pastorals: els bisbats de Girona i Vic (1587-1800), Girona.

Spanish humanism in the verge of the picaresque: Juan Maldonado's Ludus Chartarum, Pastor Bonus and Bacchanalia (2009), edición, introducción, traducción y notas de Warren Smith y Clark Colahan, Lovaina.

Szászdi León-Borja, István (2009), "Juan Rodríguez de Fonseca y los comuneros Segovianos" en Monarquía y Revolución. En torno a las Comunidades de Castilla. I Simposio Internacional de Historia Comunera, Valladolid, pp. 239-257.

Tallon, Alain (2017), La France et le concile de Trente (1518-1563), Roma.

Tellechea Idígoras, José Ignacio (1963), El obispo ideal en el siglo de la Reforma, Roma.

Tramontin, Silvio (1965), “'De officio episcopi’ di Gaspare Contarini”, Studia Patavina, 12, 1965, pp. 292-303.

Tubau, Xavier (2017), "Hispanic Conciliarism and the Imperial Politics of Reform on the Eve of the Council of Trent", Renaissance Quarterly, vol. $70 \mathrm{n}^{\circ} 3$, pp. 897-934.

Vicente Blanco, Dámaso Javier (2015), "Nacionalidad y extranjería en las Comunidades de Castilla" en Szászdi León-Borja, Itsván; Galende Ruiz, María José (eds.) Carlos V. Conversos y Comuneros. Liber Amicorum Joseph Pérez, Valladolid, pp. 399-433. 